\title{
Thermal desorption characterisation of molecularly imprinted polymers. Part II: Use of direct probe GC-MS analysis to study crosslinking effects
}

\author{
Niamh Holland • Patrick Duggan • Eleanor Owens • \\ Wayne Cummins • June Frisby • Helen Hughes • \\ Peter McLoughlin
}

Published online: 28 May 2008

(C) Springer-Verlag 2008

The authors have found an error on the $x$-axis of Fig. 4 of the above article. Please find the correct Fig. 4, with the corresponding caption, below.

Fig. 4 Binding results obtained on reloading $0.2 \mathrm{mmol} \mathrm{L}^{-1} 2$ apy in $\mathrm{CHCl}_{3}, \mathrm{ACN}$, and $\mathrm{MeOH}$ on to MIP and NIP for each polymer composition (refer to Table 1). Data are based on average values from analyses performed in triplicate

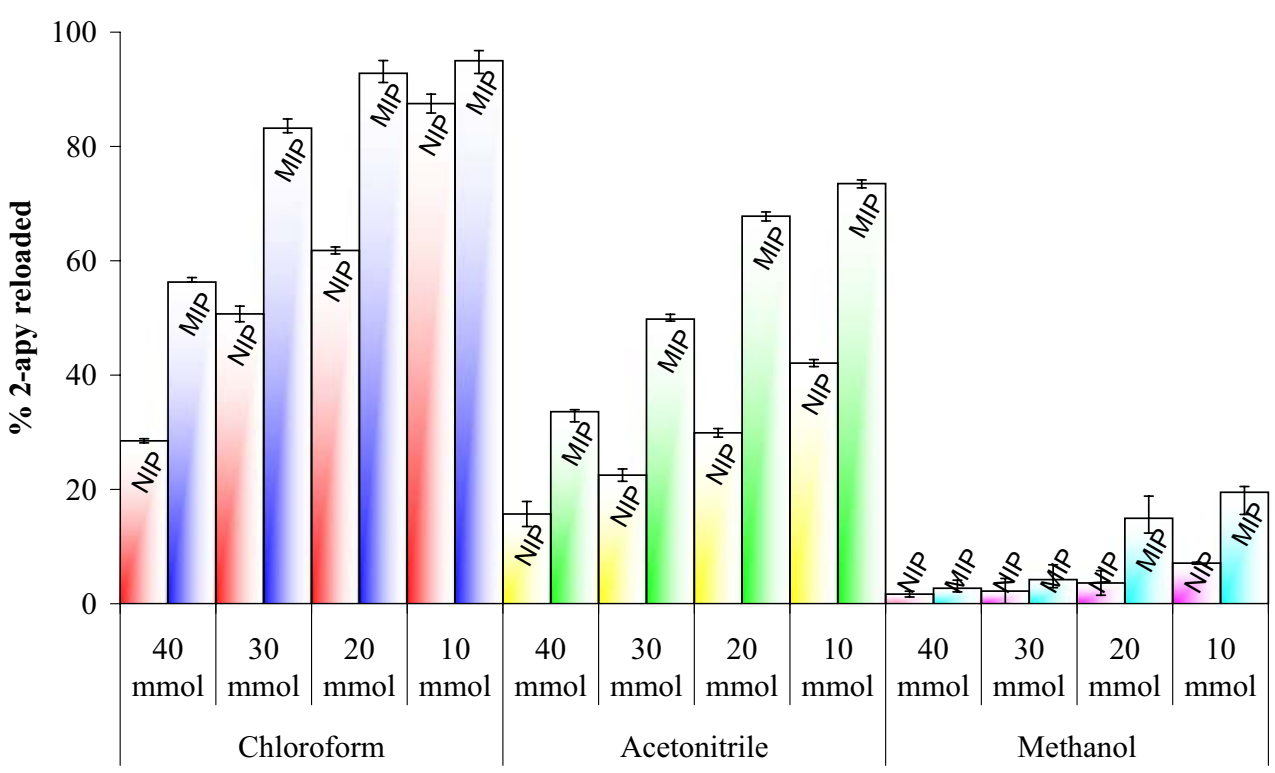

Concentration EGDMA (mmol)

The online version of the original article can be found at http://dx.doi. org/10.1007/s00216-008-1974-3.

N. Holland $(\bowtie) \cdot$ P. Duggan $\cdot$ E. Owens $\cdot$ W. Cummins $\cdot$

J. Frisby $\cdot$ H. Hughes $\cdot$ P. McLoughlin

Separation Science Research Group,

Department of Chemical and Life Sciences,

Waterford Institute of Technology,

Cork Road,

Waterford, Ireland

e-mail: nholland@wit.ie 